\title{
Management of Stage IB Grade III Endometrial Cancer: Single Institute Experience
}

\author{
Ghada Ezzat Eladawei \\ Clinical Oncology and Nuclear Medicine Department, Mansoura University, Mansoura, Egypt \\ Email: ghadaeladawy@hotmail.com
}

How to cite this paper: Eladawei, G.E. (2019) Management of Stage IB Grade III Endometrial Cancer: Single Institute Experience. Journal of Cancer Therapy, 10, 290-304.

https://doi.org/10.4236/jct.2019.104023

Received: March 7, 2019

Accepted: April 6, 2019

Published: April 9, 2019

Copyright ( 2019 by author(s) and Scientific Research Publishing Inc. This work is licensed under the Creative Commons Attribution International License (CC BY 4.0).

http://creativecommons.org/licenses/by/4.0/ (c) (i) Open Access

\begin{abstract}
Background and Objective: There is marked controversy regarding optimal management patients with stage IB grade III endometrial carcinoma. The present study analyzes the current practices regarding adjuvant radiation therapy for those patients in our institute and also assessed prognostic factor affecting overall survival outcome. Patients and Methods: A total 66 patients with postoperative FIGO stage 1B, grade III endometrial carcinoma were treated and evaluated between the years 2009 and 2014. Risk factors assessed age ( $<60$ versus $\geq 60$ ), tumor size ( $\leq 4 \mathrm{~cm}$ versus $>4 \mathrm{~cm}$ ), site of primary tumor (involvement of lower uterine segment versus no involvement), Lymphadenectomy (performed versus not performed), Lymph-vascular space invasion (positive or negative), type of surgery performed (less than total abdominal hysterectomy and bilateral salpingo-ophorectomy (TH/BSO) versus greater than or equal TH/BSO), radiation sequence with surgery (no radiation versus adjuvant radiation), and type of radiation (pelvic external beam radiotherapy versus vaginal brachytherapy versus both). Results: Adjuvant radiation therapy after surgery was associated with significantly better time to relapse ( $\mathrm{p}=$ 0.001 ) in comparison to those patients who underwent surgery alone. There was statistically significant improvement of survival of patients who received adjuvant radiation therapy in comparison with those who underwent surgery alone. There was no statistically significant difference in relapse between external pelvic radiotherapy, brachytherapy and both $(\mathrm{p}=0.161)$. There was no statistically significant difference in overall survival between different types of adjuvant radiation therapy $(\mathrm{p}=0.318)$. Adjuvant radiation therapy (HR $0.173,95 \%$ CI $0.049-0.609, \mathrm{p}=0.006)$ and tumor size (HR 4.065, 95\% CI $1.120-14.761, \mathrm{p}=0.033$ ) were the only statistically significant predictors for relapse in multivariate analysis. Adjuvant radiation therapy (HR 0.159, 95\% CI $0.045-0.563, \mathrm{p}=0.004)$, age (HR 10.357, 95\% CI $1.195-89.746, \mathrm{p}=0.034)$ and lymphadenectomy (HR 0.240, 95\% CI $0.071-0.811, \mathrm{p}=0.022$ ) were statistically significant predictors for overall survival. Conclusion: The current
\end{abstract}


study suggested that adjuvant radiation therapy definitely improve survival of patients with stage IB, grade III endometrial cancer. There is a need for more randomized trials to define patients who require adjuvant radiation therapy and define what type of radiation should be received. Well defined guidelines are very important to standardize treatment and cut costs in clinical practice.

\section{Keywords}

Endometrial Cancer, Adjuvant Radiation Therapy, External Pelvic Radiotherapy, Brachytherapy, Survival

\section{Introduction}

Endometrial cancer is the most sixth common neoplasm in women worldwide [1]. Mostly, endometrial cancer occurs over the age of fifty with a median age at diagnosis of 63 years [2]. Most of endometrial cancers are diagnosed at early stage (80\% in stage I) [3].

Endometrial carcinoma has been classified into two main clinic-pathological and molecular types; type I is the most common (80\% - 90\%) endometrioid adenocarcinoma and type II consists of non endometrioid subtypes (10\% - 20\%) such as clear cell, serous and undifferentiated carcinomas in addition carcinosarcoma/malignant-mixed Mullerian tumor [4].

Histopathologically, endometrioid is classified into three grades; 1,2 and 3. Due to high possibility of local recurrence, lymph node and distant spread, grade 3 is considered high grade [5].

In accordance with FIGO (The International Federation of Gynecology and Obstetrics) staging for endometrial cancer, stage 1 disease was further sub classified depending on the depth of tumor invasion because this is considered to be an adverse risk factor for disease outcome. In 2009, FIGO staging updated the previous 1988 version. Stage I subdivided into Stage IA included tumors with less than 50\% myometrial invasion and stage IB included tumors with more than $50 \%$ myometrial invasion, with omission of stage IC, which previously included tumors with more than $50 \%$ myometrial invasion. Therefore, prior stage IC is equal to the current stage IB [6].

Patients with stage I endometrial cancer is mainly treated with surgery. Because of low risk of local recurrence and distant metastasis, surgery alone with or without vaginal brachytherapy is often the treatment of choice of stage IA with excellent outcomes [7] [8].

Outcome of patients with stage IB widely differ. Their outcome depends on grade of tumor and presence or absence of risk factors which previously identified in large prospective trials, including age, tumor size and lymphovascular space invasion (LVSI) [9] [10].

Treatment recommendation of the major evidenced based guidelines on endometrial cancer is heterogeneous. For example, The American Society of Clini- 
cal Oncology/American Society for Radiation Oncology (ASCO/ASTRO) guidelines recommended adjuvant external beam radiation therapy to the pelvis for all patients with stage IB grade III. Furthermore, they recommended with limited evidence addition of vaginal brachytherapy after external pelvic irradiation [11].

The European Society for Medical Oncology/European Society for Radiotherapy and Oncology/European Society of Gynecological Oncology

(ESMO/ESTRO/ESGO) guidelines suggest that vaginal brachytherapy may be an alternative to external pelvic radiation therapy. Their recommendation for adjuvant external pelvic radiation is only category B (moderate or strong evidence for efficacy but with limited clinical benefit, generally recommended) [12].

Finally, recommendation of the National Comprehensive Cancer Network (NCCN) Guidelines is according to presence or absence of risk factors. They recommend vaginal brachyrherapy with or without external pelvic radiation therapy for stage IB grade III with absence of adverse risk factors or observation. Their recommendation of observation is category $2 \mathrm{~B}$ based upon lower level evidence but there is NCCN consensus that intervention is appropriate. On contrary they recommended external pelvic radiation therapy with or without vaginal brachytherapy for patient with adverse risk factors. Furthermore addition of chemotherapy is category $2 \mathrm{~B}$ recommendation [13].

Accordingly, there is marked controversy regarding optimal management patients with stage IB grade III endometrial carcinoma. The present study analyzes the current practices regarding adjuvant radiation therapy for those patients in our institute and also assessed prognostic factor affecting overall survival outcome.

\section{Patient \& Methods}

After approval by Institutional Review Board of Mansoura faculty of Medicine (IRB-MFM), this is retrospective study was conducted in clinical oncology\& nuclear medicine, Mansoura University. A total 66 eligible patients with postoperative FIGO stage 1B, grade III endometrial carcinoma were treated and evaluated between the years 2009 and 2014 .

The current analysis is limited to the years following 2009 when the new FIGO staging system was applied. Patients with stage IC (according to the old staging system) were also included which is equal to current stage IB.

\section{Inclusion criteria:}

Patients of any age with a histologically proven endometrioid carcinoma postoperative FIGO stage IB grade 3 were eligible for the study (stage IB included tumors with more than 50\% myometrial invasion). Poorly or un-differentiated endometrioid carcinomas were also included in our analysis.

Exclusion criteria:

Patients for whom the radiation sequence with surgery was unknown or lost follow up also excluded from the study.

\section{Study objectives:}


The primary objective of this study is compared each type of treatment received to stage IB, grade III endometrial carcinoma.

Risk factors assessed age ( $<60$ versus $\geq 60$ ), tumor size ( $\leq 4 \mathrm{~cm}$ versus $>4 \mathrm{~cm}$ ), site of primary tumor (involvement of lower uterine segment versus no involvement), Lymphadenectomy (performed versus not performed), Lymph-vascular space invasion (positive or negative) type of surgery performed (less than Total abdominal hysterectomy and bilateral salpingo-ophorectomy (TH/BSO) versus greater than or equal TH/BSO), radiation sequence with surgery (no radiation versus adjuvant radiation), and type of radiation (pelvic external beam radiotherapy versus vaginal brachytherapy versus both).

\section{Follow up:}

Chest X-ray and abdominal-pelvic CT or MRI were conducted every six months for the first two years post-surgery and then annually.

\section{Statistical analysis:}

Data were entered and analyzed using IBM-SPSS software (Version 25.0. Armonk, NY: IBM Corp.). Qualitative data were expressed as frequency and percentage. Quantitative data were initially tested for normality using Kolmogorov-Smirnov and Shapiro-Wilk's test with data being normally distributed if $\mathrm{p}>$ 0.050 . Quantitative data were expressed as mean \pm standard deviation (SD). Qualitative data were compared by Chi-Square test (or Fisher's exact test). Monte Carlo significance was used when appropriate. Bonferroni method to adjust $\mathrm{p}$ values when comparing column proportions was also used. Quantitative data between two groups were compared by Independent-Samples t-test if data were normally distributed in both groups. The non-parametric alternative Mann-Whitney $\mathrm{U}$ test was used if not. Quantitative data between more than two groups were compared by One-way ANOVA test if data were normally distributed in all groups. The non-parametric alternative Kruskal-Wallis $\mathrm{H}$ test was used if not. Pairwise comparisons were performed if the result was significant to detect where that significant difference existed. The Kaplan-Meier method was used to estimate the probability of survival past given time points (i.e. it calculates a survival distribution). The survival distributions of two or more groups of a between-subjects factor can be compared for equality using log-rank test. Cox regression analysis was used to predict survival. For any of the used tests, results were considered as statistically significant if $\mathrm{p}$ value $\leq 0.050$.

\section{Results}

This study included 66 patients with stage IB grade III endometrial carcinoma with mean age \pm SD of $60.6 \pm 6.1$ years. Most of the patients underwent total abdominal hystrectomy and bilateral salpingo-oophrectomy, only $7.6 \%$ of patients underwent substandard surgery. Thirty seven tumors (56.1\%) were larger than $4 \mathrm{~cm}$. Twenty six tumors (39.4\%) showed involvement of lower uterine segment. Most of the patients (74.2\%) underwent lymphadenectomy. Lymphovascular space invasion (LVSI) was present in $34.8 \%$ of tumors, absent in $42.4 \%$ of tumors and not assessed in $22.7 \%$ of tumors. Twenty patients (30.3\%) did not 
receive adjuvant radiation therapy. 46 patients $(69.7 \%)$ received adjuvant radiation therapy. Among those patients, 16 (24.2\%) received external pelvic radiation, $14(21.2 \%)$ received brachytherapy, and $16(24.2 \%)$ received both (brachytherapy and external pelvic radiation). Fourteen patients $(21.2 \%)$ had relapse, ten of them $(15.1 \%)$ were pelvic relapse and four patients $(6.1 \%)$ presented with vaginal relapse (Table 1$)$.

Table 1. Clinico-pathological characteristics of the patients and treatment pattern $(\mathrm{n}=$ 66).

\begin{tabular}{|c|c|c|}
\hline Variable & Frequency & Percentage \\
\hline \multicolumn{3}{|l|}{ Age category: } \\
\hline$<60$ years & 26 & $39.4 \%$ \\
\hline$\geq 60$ years & 40 & $60.6 \%$ \\
\hline \multicolumn{3}{|l|}{ Surgery type: } \\
\hline TAH \& BSO & 61 & $92.4 \%$ \\
\hline Subtotal hysterectomy & 5 & $7.6 \%$ \\
\hline \multicolumn{3}{|l|}{ Tumor size: } \\
\hline$\leq 4 \mathrm{~cm}$ & 37 & $56.1 \%$ \\
\hline$>4 \mathrm{~cm}$ & 29 & $43.9 \%$ \\
\hline \multicolumn{3}{|l|}{ Lower uterine segment: } \\
\hline Involved & 26 & $39.4 \%$ \\
\hline Not involved & 40 & $60.6 \%$ \\
\hline \multicolumn{3}{|l|}{ Lymphadenectomy: } \\
\hline Done & 49 & $74.2 \%$ \\
\hline Not done & 17 & $25.8 \%$ \\
\hline \multicolumn{3}{|l|}{ Lymphovascular space invasion: } \\
\hline Present & 23 & $34.8 \%$ \\
\hline Absent & 28 & $42.4 \%$ \\
\hline Not assessed & 15 & $22.7 \%$ \\
\hline \multicolumn{3}{|l|}{ Post-operative treatment type: } \\
\hline No adjuvant radiation therapy & 20 & $30.3 \%$ \\
\hline Adjuvant radiation therapy & 46 & $69.7 \%$ \\
\hline \multicolumn{3}{|l|}{ Type of adjuvant radiation therapy: } \\
\hline External pelvic radiotherapy & 16 & $24.2 \%$ \\
\hline Vaginal brachytherapy & 14 & $21.2 \%$ \\
\hline Both & 16 & $24.2 \%$ \\
\hline \multicolumn{3}{|l|}{ Relapse: } \\
\hline Yes & 14 & $21.2 \%$ \\
\hline No & 52 & $78.8 \%$ \\
\hline \multicolumn{3}{|l|}{ Site of relapse: } \\
\hline Pelvic & 10 & $15.1 \%$ \\
\hline Vaginal & 4 & $6.1 \%$ \\
\hline
\end{tabular}

TAH \& BSO total abdominal hysterectomy and bilateral salpingo-ophrectomy. 
There were no statistically significant difference in any of clinic-pathological factors tested between patients who underwent surgery alone and those who received adjuvant radiation therapy. Relapse was statistically significantly higher in patients who underwent surgery alone (Table 2).

Disease outcome:

Survival outcome of 66 patients with Stage IB grade III endometrial carcinoma were analyzed. After median follow up period 50 months (range 9 - 72 month). Fourteen patients were died from endometrial cancer at the end of follow up.

Table 2. Comparisons of clinic-pathological characteristics according type of treatment received.

\begin{tabular}{|c|c|c|c|c|}
\hline \multirow[b]{2}{*}{ Variable } & \multicolumn{2}{|r|}{ Treatment arm } & \multirow[b]{2}{*}{$x^{2}$} & \multirow[b]{2}{*}{$\mathrm{p}$ value } \\
\hline & $\begin{array}{l}\text { Surgery } \\
(\mathrm{n}=20)\end{array}$ & $\begin{array}{c}\text { Surgery and adjuvant } \\
\text { radiation therapy }(\mathrm{n}=46)\end{array}$ & & \\
\hline \multicolumn{5}{|l|}{ Age category: } \\
\hline$<60$ years & $7(35 \%)$ & $19(41.3 \%)$ & 0.232 & 0.630 \\
\hline$\geq 60$ years & $13(65 \%)$ & $27(58.7 \%)$ & & \\
\hline \multicolumn{5}{|l|}{ Surgery type: } \\
\hline $\mathrm{TAH}+\mathrm{BSO}$ & $20(100 \%)$ & $41(89.1 \%)$ & 2.352 & $0.312^{\star}$ \\
\hline Subtotal hysterectomy & $0(0 \%)$ & $5(10.9 \%)$ & & \\
\hline \multicolumn{5}{|l|}{ Tumor size: } \\
\hline$\leq 4 \mathrm{~cm}$ & $10(50 \%)$ & $27(58.7 \%)$ & 0.428 & 0.513 \\
\hline$>4 \mathrm{~cm}$ & $10(50 \%)$ & $19(41.3 \%)$ & & \\
\hline \multicolumn{5}{|l|}{ Lower uterine segment: } \\
\hline Involved & $8(40 \%)$ & $18(39.1 \%)$ & 0.004 & 0.947 \\
\hline Not involved & $12(60 \%)$ & $28(60.9 \%)$ & & \\
\hline \multicolumn{5}{|l|}{ Lymphadenectomy: } \\
\hline Done & $16(80 \%)$ & $33(71.74 \%)$ & 0.497 & 0.481 \\
\hline Not done & $4(20 \%)$ & $13(28.26 \%)$ & & \\
\hline \multicolumn{5}{|c|}{ Lymphovascular space invasion: } \\
\hline Present & $3(15 \%)$ & $20(43.48 \%)$ & & \\
\hline Absent & $11(55 \%)$ & $17(36.96 \%)$ & 4.982 & $0.097^{\star *}$ \\
\hline Not assessed & $6(30 \%)$ & $9(19.56 \%)$ & & \\
\hline \multicolumn{5}{|l|}{ Relapse: } \\
\hline Yes & $9(45 \%)$ & $5(10.9 \%)$ & 9.716 & $0.003^{*}$ \\
\hline No & $11(55 \%)$ & $41(89.1 \%)$ & & \\
\hline
\end{tabular}

Data are expressed as frequency (percentage). $\mathrm{p}$ value by Chi-Square test, ${ }^{*}$ Fisher's Exact test, or ${ }^{*}$ Monte Carlo significance test. 
Adjuvant radiation therapy after surgery was associated with significantly better time to relapse $(\mathrm{p}=0.001)$ in comparison to those patients who underwent surgery alone (observation group) (Figure 1). There was statistically significant improvement of survival of patients who received adjuvant radiation therapy in comparison with those who underwent surgery alone (observation group) ( $\mathrm{p}=$ 0.008) (Figure 2).

Log-Rank was used for comparing time to relapse and overall survival between different types of adjuvant radiation therapy. There was no statistically significant difference in relapse between external pelvic radiotherapy, vaginal brachytherapy and both ( $\mathrm{p}=0.161$ ) (Figure 3 ). Also, there was no statistically significant difference in overall survival between different types of adjuvant radiation therapy $(\mathrm{p}=0.318)$ (Figure 4$)$.

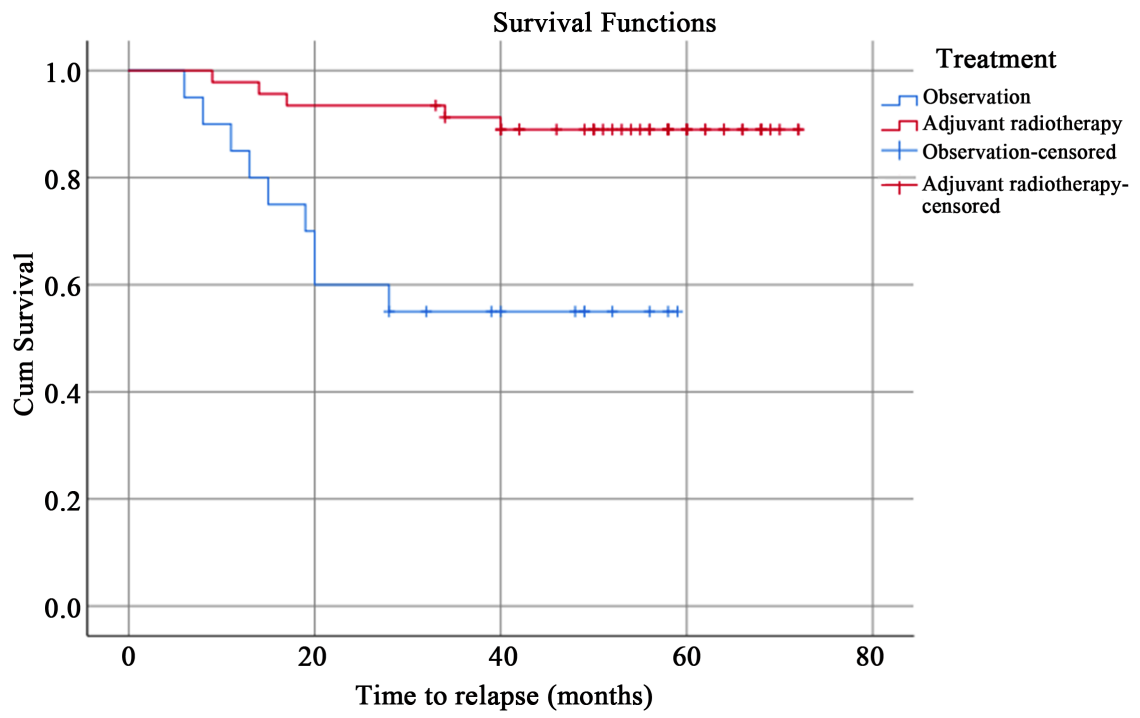

Figure 1. Kaplan-Meier curve for time to relapse according to treatment.

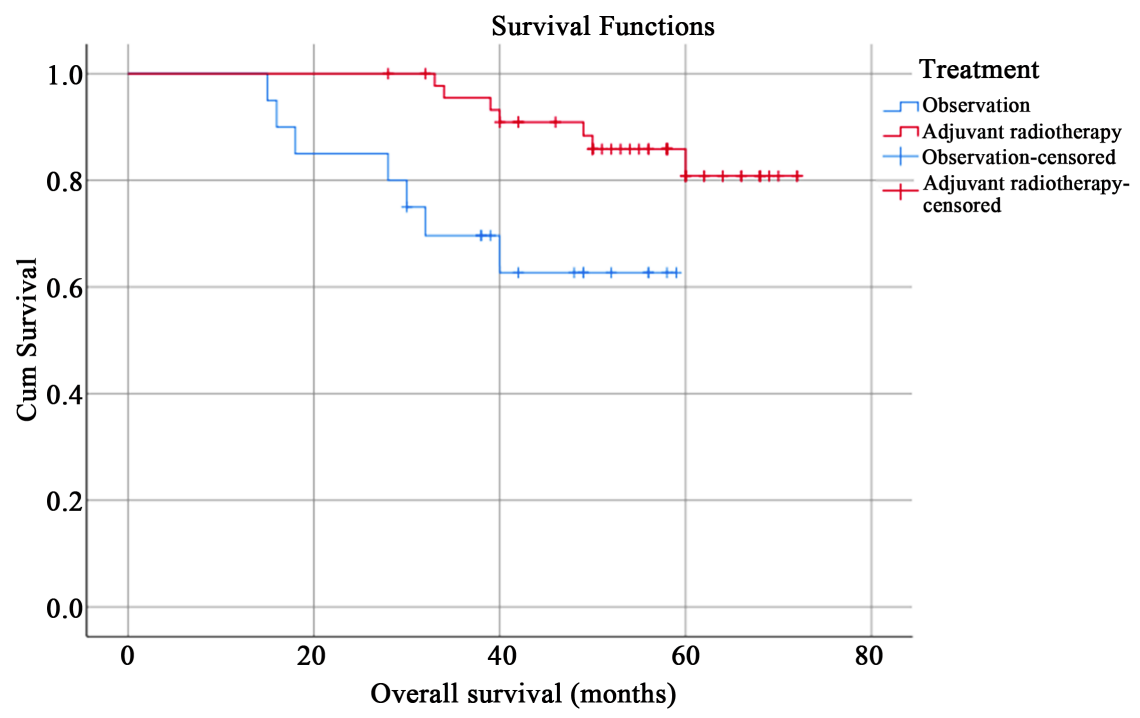

Figure 2. Kaplan-Meier curve for overall survival according to treatment. 


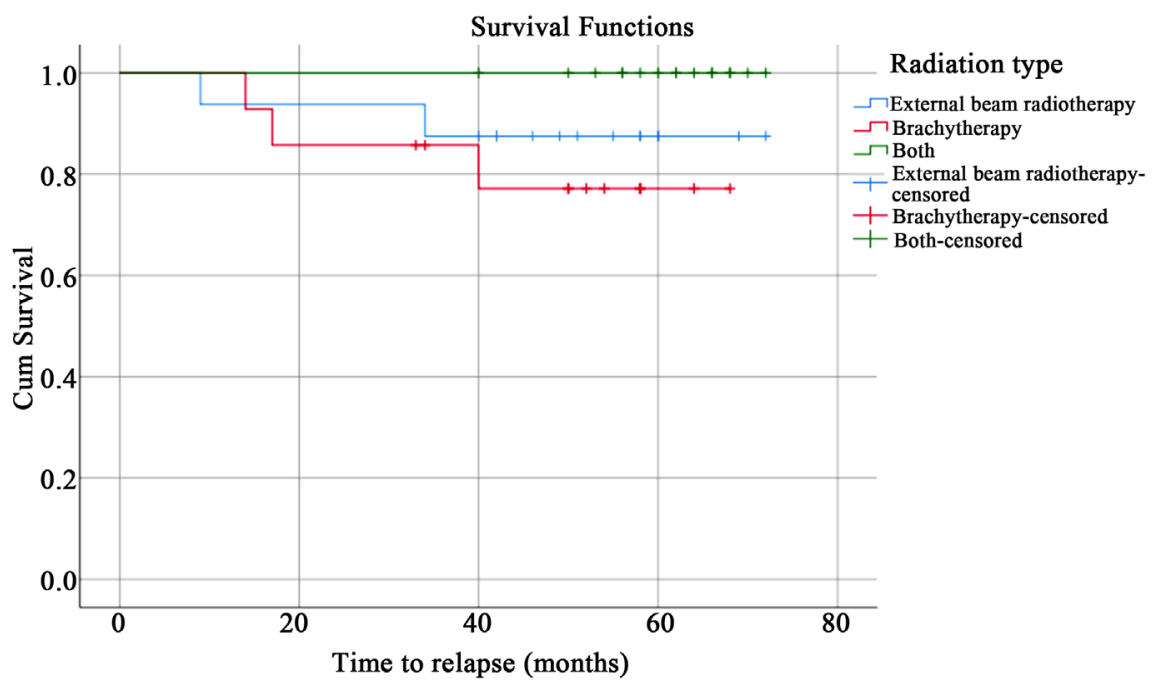

Figure 3. Kaplan-Meier curve for relapse according to radiation therapy type.

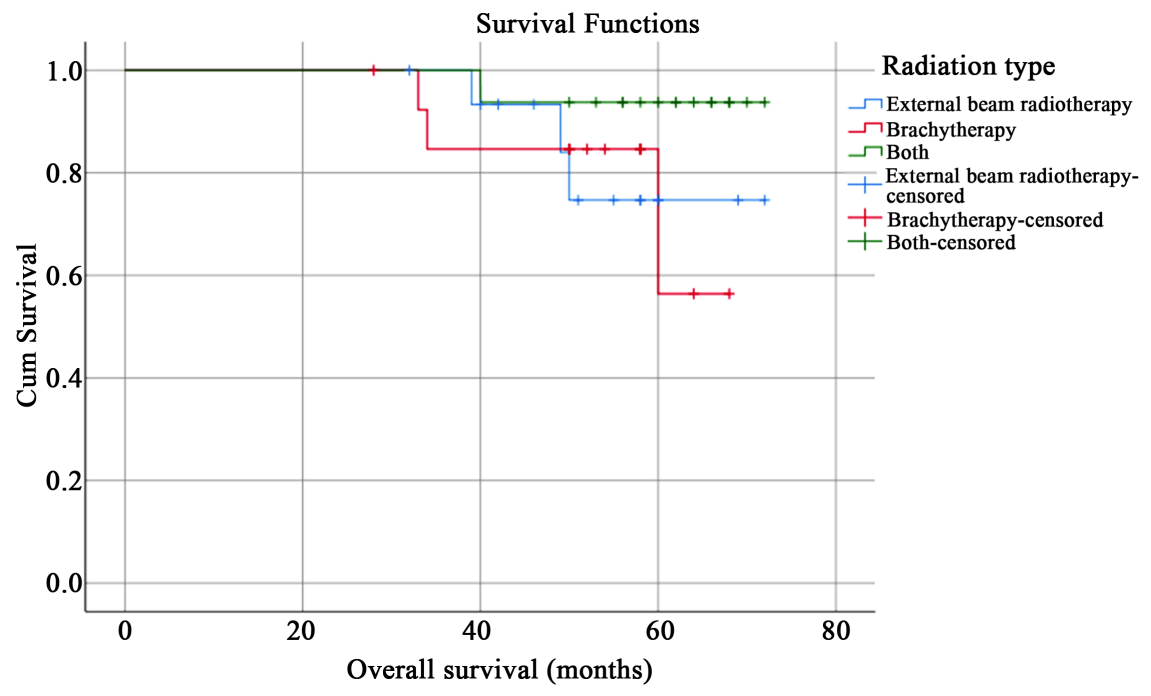

Figure 4. Kaplan-Meier curve for overall survival according to radiation therapy type.

Cox regression analysis of factors potentially affected relapse was done. The following factors were analyzed, treatment received, age, type of surgery, tumor size, lymphadenectomy and lymphovascular space invasion (LVSI). In univariate analysis, treatment (surgery alone versus surgery and adjuvant radiation therapy) (HR 5.437, 95\% CI $1.810-16.332, \mathrm{p}=0.003)$ and tumor size $(\leq 4 \mathrm{~cm},>4 \mathrm{~cm})$ (HR 3.942, 95\% CI $1.234-12.587, \mathrm{p}=0.021$ ) were the only statistically significant factors. Also in multivariate analysis; treatment (HR 0.173, 95\% CI 0.049 $0.609, \mathrm{p}=0.006$ ), tumor size (HR 4.065, 95\% CI $1.120-14.761, \mathrm{p}=0.033$ ) and lymphadenectomy (HR $0.270,95 \%$ CI $0.078-0.933, \mathrm{p}=0.039$ ) were the only statistically significant predictors for relapse (Table 3 ).

Cox regression analysis of factors potentially affected overall survival was done. The following factors were tested, treatment received, age, tumor size, tumor site and lymphadenectomy. In univariate analysis, treatment (surgery alone 
versus surgery and adjuvant radiation therapy) (HR 4.006, 95\% CI 1.329 $12.069, \mathrm{p}=0.014)$, age (HR 13.518, 95\% CI $1.694-107.901, \mathrm{p}=0.014$ ) and tumor size (HR 3.896, 95\% CI 1.219 - 12.455, p = 0.022) were statistically significant factors for overall survival. In multivariate analysis; treatment (HR 0.159, 95\% CI $0.045-0.563, \mathrm{p}=0.004)$, age (HR 10.357, 95\% CI $1.195-89.746, \mathrm{p}=$ 0.034 ) and lymphadenectomy (HR 0.240, 95\% CI $0.071-0.811, \mathrm{p}=0.022$ ) were statistically significant predictors for overall survival (Table 4).

Table 3. Cox regression analysis of prognostic factors of relapse.

\begin{tabular}{|c|c|c|c|c|c|c|}
\hline \multirow{2}{*}{ variable } & \multicolumn{3}{|c|}{ Univariate analysis } & \multicolumn{3}{|c|}{ Multivariate analysis } \\
\hline & HR & $95 \% \mathrm{CI}$ & $\mathrm{p}$ value & HR & $95 \% \mathrm{CI}$ & $\mathrm{p}$ value \\
\hline \multicolumn{7}{|l|}{ Treatment: } \\
\hline Surgery & 5.437 & $1.810-16.332$ & 0.003 & 0.173 & $0.049-0.609$ & 0.006 \\
\hline \multicolumn{7}{|c|}{ Surgery and adjuvant radiation } \\
\hline \multicolumn{7}{|l|}{ Age: } \\
\hline$<60$ years & 1.879 & $0.589-5.994$ & 0.287 & 1.161 & $0.287-4.701$ & 0.835 \\
\hline$\geq 60$ years & & & & & & \\
\hline \multicolumn{7}{|l|}{ Type of surgery: } \\
\hline $\mathrm{TAH}+\mathrm{BSO}$ & 0.866 & $0.110-6.421$ & 0.866 & 0.718 & $0.142-3.638$ & 0.689 \\
\hline \multicolumn{7}{|c|}{ Subtotal surgery } \\
\hline \multicolumn{7}{|l|}{ Tumor size: } \\
\hline$\leq 4 \mathrm{~cm}$ & 3.942 & $1.234-12.587$ & 0.021 & 4.065 & $1.120-14.761$ & 0.033 \\
\hline$>4 \mathrm{~cm}$ & & & & & & \\
\hline \multicolumn{7}{|l|}{ lower uterine segment: } \\
\hline Involved & 0.867 & $0.301-2.500$ & 0.792 & 0.754 & $0.216-2.632$ & 0.657 \\
\hline \multicolumn{7}{|l|}{ Not involved } \\
\hline \multicolumn{7}{|l|}{ Lymphadenectomy: } \\
\hline Done & 0.399 & $0.138-1.150$ & 0.089 & 0.270 & $0.078-0.933$ & 0.039 \\
\hline Not done & & & & & & \\
\hline \multicolumn{7}{|l|}{ LVSI: } \\
\hline Abscent & 0.781 & $0.220-2.769$ & 0.702 & 0.783 & $0.188-3.270$ & 0.738 \\
\hline Present & & & & & & \\
\hline
\end{tabular}

Table 4. Cox regression analysis of prognostic factors affected overall survival.

\begin{tabular}{|c|c|c|c|c|c|c|}
\hline \multirow{2}{*}{ variable } & \multicolumn{3}{|c|}{ Univariate analysis } & \multicolumn{3}{|c|}{ Multivariate analysis } \\
\hline & $\mathrm{HR}$ & $95 \%$ CI & $\mathrm{p}$ value & $\mathrm{HR}$ & $95 \%$ CI & $\mathrm{p}$ value \\
\hline \multicolumn{7}{|l|}{ Treatment: } \\
\hline Surgery & 4.006 & $1.329-12.069$ & 0.014 & 0.159 & $0.045-0.563$ & 0.004 \\
\hline \multicolumn{7}{|c|}{ Surgery and adjuvant radiation } \\
\hline \multicolumn{7}{|l|}{ Age: } \\
\hline$<60$ years & 13.518 & $1.694-107.901$ & 0.014 & 10.357 & $1.195-89.746$ & 0.034 \\
\hline$\geq 60$ years & & & & & & \\
\hline \multicolumn{7}{|l|}{ Tumor size: } \\
\hline$\leq 4 \mathrm{~cm}$ & 3.896 & $1.219-12.455$ & 0.022 & 2.675 & $0.786-9.105$ & 0.115 \\
\hline$>4 \mathrm{~cm}$ & & & & & & \\
\hline \multicolumn{7}{|l|}{ lower uterine segment: } \\
\hline Involved & 1.162 & $0.389-3.469$ & 0.788 & 0.696 & $0.220-2.203$ & 0.538 \\
\hline \multicolumn{7}{|l|}{ Not involved } \\
\hline \multicolumn{7}{|l|}{ Lymphadenectomy: } \\
\hline Done & 0.413 & $0.143-1.194$ & 0.102 & 0.240 & $0.071-0.811$ & 0.022 \\
\hline Not done & & & & & & \\
\hline
\end{tabular}




\section{Discussion}

FIGO stage I endometrial cancer circumscribes various group of cancers whose treatment is not well understood. Published GOG33 paper in 1987 assessed the surgical pathological features of stage I endometrial cancer patients [14]. The authors identified prognostic factors which were associated with increased risk of extrauterine spread. Depth of myometrium invasion and tumor grade were the most significant risk factors. Invasion of the outer third of the myometrium had a $25 \%$ risk for pelvic lymph node metastasis versus $5 \%$ for those with disease limited to inner third. Also there was an $18 \%$ risk of positive pelvic nodes for poorly differentiated tumor versus $3 \%$ for well differentiated tumors. Additional pathological features were also identified that increased the possibility of disease spread to pelvic nodes, including positive peritoneal cytology, presence of lymphovascular space invasion and involvement of lower uterine segment.

After publication of GOG33, large randomized trials had been published evaluating the role of adjuvant radiation therapy in early stage endometrial cancer [7] [15] [16] [17]. There were lack of uniformity among those trials in definitions of risk groups and study arms in each trial differed as type of adjuvant treatment received according to judgment of treating physician.

In these trials, patients were randomized after surgery (total abdominal hysterectomy and bilateral salpingo-ophorectomy) to external beam radiation therapy or observation. The three trials and meta-analysis by Kong et al. [17] observed that external beam radiation therapy reduced risk of recurrence from $14 \%$ to $4 \%$, but did not achieve any overall survival benefit and associated with significant morbidity.

PORTEC-1 trial [16] defined risk groups according risk factors for locoregional recurrence (age $>60$ years, deep ( $\geq 50 \%)$ myometrial invasion, grade 3 ). High-intermediate risk patients defined as presence of two of three of these risks.

GOG99 trial [7] defined high-intermediate risk patients as age $<50$ years and one risk factor, age 50 - 70 years and two risk factors and age $>70$ and all three risk factors. PORTEC-2 randomized trial included only high-intermediate risk patients that defined in PORTEC-1. PORTEC-2 reported that vaginal brachytherapy provided excellent vaginal control compared with external beam radiotherapy and associated with less morbidity [18]. Furthermore, Swedish trial compared vaginal brachytherapy with combined external beam radiotherapy and vaginal brachytherapy. Their result confirmed PORTEC-2 observation [19].

MRC ASTEC trial [15] and ESMO guide lines [12] classified patients with stage I as high risk if there are adverse prognostic factors. Patients with stage IB grade III tumors are classified as high risk patients.

Data from previous randomized trials provide strong evidence that adjuvant radiation therapy is improving local control, but not overall survival in patients with high grade deeply invasive stage I endometrial cancer. PORTEC-3 randomized trial was aiming to intensify treatment beyond radiation alone. The randomization was between adjuvant radiation therapy alone versus adjuvant che- 
motherapy and radiation therapy. PORTEC- 3 trail included patients with stage IB grade III. The authors observed inferior survival outcome among those high risk patients. Only toxicity and quality of life data, but not survival outcome had been reported in this study [20].

The current study presents information on practice pattern regarding the use of adjuvant radiation therapy for stage I grade III endometrioid adenocarcinoma of the uterus. In this study, $30 \%$ of patients did not receive adjuvant radiation therapy. Similarly a recent study from National Cancer Data Base (NCDB) showed that $52 \%$ of patients with stage IB (any grade) did not receive adjuvant radiation therapy [21].

This finding suggests discrepancy between national guidelines and common practice. This may be explained heterogeneity in groups of patients included in the previous clinical trials and heterogeneity in the treatment arms, making it difficult to define exactly which patients would gain the benefit from adjuvant radiation therapy.

The current study showed adjuvant radiation therapy after surgery was associated with statistically significant better local control and improvement of survival in comparison to those patients who underwent surgery. Similar observation was reported by Harkenrider et al. [22]. The authors performed large analysis of stage I endometrial cancer endometrioid type to define impact of adjuvant radiotherapy on survival. They showed that adjuvant radiation therapy significantly improves survival in patients with high-intermediate and high risk endometriod type. Furthermore, recent National Cancer Data base (NCDB) analyzed 33,600 high-intermediate risk 2009 FIGO stage I patients. They defined according to ASTRO guidelines as stage IB and/or grade III. There was statistically significant improvement of survival for patients who received post operative radiotherapy after surgery than those who underwent surgery alone [23].

On the other hand, several randomized trials and meta-analyses did not show improvement of survival [17]. The first systematic review and meta-analysis showed a trend towards better survival in high risk patients treated with postoperative radiotherapy but this was not statistically significant [24]. This observation was lost after ASTEC-ENS results. The effect of vaginal brachytherapy alone is difficult to be clarified because only one randomized trial compared brachytherapy with observation among low risk patients [25].

The PORTEC-1 was planned to detect five years survival benefit of $10 \%$ for adjuvant external beam radiotherapy. This trial included around 700 patients, but given the low event rates, would have required more than 2000 patients per arm [22]. The sample size and the event rate deficit were aggravated by inclusion of low grade minimally invasive tumors which had low risk for relapse with no need for adjuvant treatment. Furthermore PORTEC-1 excluded stage 1 grade III patients and only one third of the patients (132) were high risk criteria according to GOG-99 trial, despite the fact that this group accounted for two thirds of the cancer related deaths [5]. 
The current study observed that there was no statistically significant difference in relapse between external pelvic radiotherapy, vaginal brachytherapy and both. Also, there was no statistically significant difference in overall survival between different types of adjuvant radiation therapy. Similarly, PORTEC-2 trial stated that there was no difference in locoregional relapse or overall survival between vaginal brachytherapy and external beam radiotherapy for patients with endometrial cancer of high-intermediate risk [18]. The Surveillance, Epidemiology, and End Results (SEER) data base has been assessed the value of addition of vaginal brachytherapy after external pelvic radiotherapy in patients with high risk stage I and II endometrial carcinoma. There was no statistically difference in overall 5 year and 10 year survival for external pelvic radiotherapy and addition of brachytherapy to external pelvic radiotherapy [26].

The current study analyzed factors potentially affected relapse and overall survival. The prognostic value of positive peritoneal washing is debatable.

The majority of studies found that positive peritoneal washings were independent prognostic factor [27] [28] [29]. Currently, the following factors were analyzed, treatment received, age, type of surgery, tumor size, lymphadenectomy and lymphovascular space invasion (LVSI). In multivariate analysis treatment (HR 0.173, 95\% CI $0.049-0.609, \mathrm{p}=0.006)$ and tumor size (HR 4.065, 95\% CI $1.120-14.761, \mathrm{p}=0.033)$ were the only statistically significant predictors for relapse. Schink et al. (10) stated that tumor size is negatively affect outcome.

Multivariate analysis of factors potentially affected overall survival found that treatment (HR 0.159, 95\% CI $0.045-0.563, \mathrm{p}=0.004)$, age (HR 10.357, 95\% CI 1.195 - 89.746, $\mathrm{p}=0.034$ ) and lymphadenectomy (HR 0.240, 95\% CI 0.071 $0.811, \mathrm{p}=0.022)$ were statistically significant predictors for overall survival. Many studies showed that age is important predictor for survival [7] [14] [18]. A study by Chino et al. [30] assessed the effect of radiation modality and lymph node dissection on survival in early stage endometrial cancer including stage IB, grade III. The authors stated that both lymph node dissection and adjuvant radiation improved overall survival.

\section{Conclusion}

Despite that this study is retrospective study with limited number of cases, it highlights the variation in the current practice in the management of patients with stage IB, grade III endometrioid carcinoma of the uterus. The current study suggested that adjuvant radiation therapy definitely improve survival of patients with stage IB, grade III. There is a need for more randomized trials to define patients who require adjuvant radiation therapy and define what type of radiation should be received. Well defined guidelines are very important to standardize treatment and cut costs in clinical practice.

\section{Conflicts of Interest}

The author declares no conflicts of interest regarding the publication of this paper. 


\section{References}

[1] Lortet-Tieulent, J., Ferlay, J., Bray, F. and Jemal, A. (2018) International Patterns and Trends in Endometrial Cancer Incidence, 1978-2013. Journal of the National Cancer Institute, 110, 354-361. https://doi.org/10.1093/jnci/djx214

[2] Lee, N.K., Cheung, M.K., Shin, J.Y., Husain, A., Teng, N.N., Berek, J.S., Kapp, D.S., Osann, K. and Chan, J.K. (2007) Prognostic Factors for Uterine Cancer in Reproductive-Aged Women. Obstetrics \& Gynecology, 109, 655-662.

https://doi.org/10.1097/01.AOG.0000255980.88205.15

[3] National Cancer Institute Endometrial Cancer Treatment. http://www.cancer.gov/types/uterine/hp/endometrial-treatment-pdq

[4] Buhtoiarova, T.N., Brenner, M. and Singh, C.A. (2016) Endometrial Carcinoma: Role of Current and Emerging Biomarkers in Resolving Persistent Clinical Dilemmas. AJCP, 145, 8-21. https://doi.org/10.1093/ajcp/aqv014

[5] Creutzberg, C.L., Nout, R.A., Lybeert, M.L.M., Rodenhuis, C.W., Jobsen, J.J., Mens, J.W., Lutgens, L.C., Elisabeth, P., van de Poll-Franse, L.V. and Van Putten, W.J. (2011) Fifteen-Year Radiotherapy Outcomes of the Randomized PORTEC-1 Trial for Endometrial Carcinoma. International Journal of Radiation Oncology, Biology, Physics, 81, e631-e638.

[6] Mutch, D. (2009) The New FIGO Staging System for Cancers of the Vulva, Cervix, Endometrium, and Sarcomas. Gynecologic Oncology, 115, 325-328.

https://doi.org/10.1016/j.ygyno.2009.10.050

[7] Keys, H.M., Roberts, J.A., Brunetto, V.L., Zaino, R.J., Spirtos, N.M., Bloss, J.D., Pearlman, A., Maiman, M.A. and Bell, J.G. (2004) A Phase III Trial of Surgery with or without Adjunctive External Pelvic Radiation Therapy in Intermediate Risk Endometrial Adenocarcinoma: A Gynecologic Oncology Group Study. Gynecologic Oncology, 92, 744-751.

[8] Straughn, J.M., Huh, W.K., Kelly, F.J., Leath 3rd, C.A., Kleinberg, M.J., Hyde, J., Numnum, T.M., Zhang, Y., Soong, S.J., Austin, J.M., Partridge, E.E., Kilgore, L.C. and Alvarez, R.D. (2002) Conservative Management of Stage I Endometrial Carcinoma after Surgical Staging. Gynecologic Oncology, 84, 194-200.

https://doi.org/10.1006/gyno.2001.6494

[9] Bosse, T., Peters, E.E.M., Creutzberg, C.L., urgenliemk-Schulz, I.M., Jobsen, J.J., Mens, J.W.M., Lutgens, L.C.H., van der Steen-Banasik, E.M., Smit, V.T.H. and Nout, R.A. (2015) Substantial Lymph-Vascular Space Invasion (LVSI) Is a Significant Risk Factor for Recurrence in Endometrial Cancer-A Pooled Analysis of PORTEC 1 and 2 Trials. European Journal of Cancer, 51, 1742-1750. https://doi.org/10.1016/j.ejca.2015.05.015

[10] Schink, J.C., Rademaker, A.W., Miller, D.S. and Lurain, J.R. (1991) Tumor Size in Endometrial Cancer. Cancer, 67, 2791-2794.

https://doi.org/10.1002/1097-0142(19910601)67:11<2791::AID-CNCR2820671113> 3.0.CO;2-S

[11] Klopp, A., Smith, B.D., Alektiar, K., Cabrera, A., Damato, A.L., Erickson, B., Fleming, G., Gaffney, D., Greven, K., Lu, K., Miller, D., Moore, D., Petereit, D., Schefter, T., Small, W., Yashar, C. and Viswanathan, A.N. (2014) The Role of Postoperative Radiation Therapy for Endometrial Cancer: Executive Summary of an American Society for Radiation Oncology Evidence-Based Guideline. Practical Radiation Oncology, 4, 137-144. https://doi.org/10.1016/j.prro.2014.01.003

[12] Colombo, N., Creutzberg, C., Amant, F., Bosse, T., González-Martín, A., Ledermann, J., Marth, C., Nout, R., Querleu, D., Mirza, M.R. and Sessa, C. (2016) 
ESMO-ESGOESTRO Consensus Conference on Endometrial Cancer: Diagnosis, Treatment and Follow-Up. Annals of Oncology, 27, 16-41. https://doi.org/10.1093/annonc/mdv484

[13] https://www.nccn.org/professionals/physician_gls/pdf/uterine.pdf

[14] Creasman, W.T., Morrow, C.P., Bundy, B.N., Homesley, H.D., Graham, J.E. and Heller, P.B. (1987) Surgical Pathologic Spread Patterns of Endometrial Cancer: A Gynecologic Oncology Group Study. Cancer, 60, 2035-2041.

https://doi.org/10.1002/1097-0142(19901015)60:8+<2035::AID-CNCR2820601515> 3.0.CO;2-8

[15] Blake, P., Swart, A.M., Orton, J., Kitchener, H., Whelan, T., Lukka, H., Eisenhauer, E., Bacon, M., Tu, D., Parmar, M.K., Amos, C., Murray, C. and Qian, W. (2009) Adjuvant External Beam Radiotherapy in the Treatment of Endometrial Cancer (MRC ASTEC and NCIC CTG EN.5 Randomised Trials): Pooled Trial Results, Systematic Review, and Meta-Analysis. The Lancet, 373, 137-146.

https://doi.org/10.1016/S0140-6736(08)61767-5

[16] Creutzberg, C.L., van Putten, W.L., Koper, P.C., Lybeert, M.L., Jobsen, J.J., Wárlám-Rodenhuis, C.C., De Winter, K.A., Lutgens, L.C., van den Bergh, A.C., van de Steen-Banasik, E., Beerman, H. and van Lent, M. (2000) Surgery and Postoperative Radiotherapy versus Surgery Alone for Patients with Stage-1 Endometrial Carcinoma: Multicentre Randomised Trial. PORTEC Study Group. Post Operative Radiation Therapy in Endometrial Carcinoma. The Lancet, 355, 1404-1411. https://doi.org/10.1016/S0140-6736(00)02139-5

[17] Kong, A., Johnson, N., Kitchener, H.C. and Lawrie, T.A. (2012) Adjuvant Radiotherapy for Stage I Endometrial Cancer: An Updated Cochrane Systematic Review and Meta-Analysis. Journal of the National Cancer Institute, 104, 1625-1634. https://doi.org/10.1093/jnci/djs374

[18] Nout, R.A., Smit, V.T., Putter, H., Jürgenliemk-Schulz, I.M., Jobsen, J.J., Lutgens, L.C., van der Steen-Banasik, E.M., Mens, J.W., Slot, A., Kroese, M.C., van Bunningen, B.N., Ansink, A.C., van Putten, W.L. and Creutzberg, C.L. (2010) Vaginal Brachytherapy versus Pelvic External Beam Radiotherapy for Patients with Endometrial Cancer of High-Intermediate Risk (PORTEC-2): An Open-Label, Non-Inferiority, Randomised Trial. The Lancet, 375, 816-823.

https://doi.org/10.1016/S0140-6736(09)62163-2

[19] Sorbe, B., Horvath, G., Andersson, H., Boman, K., Lundgren, C. and Pettersson, B. (2012) External Pelvic and Vaginal Irradiation versus Vaginal Irradiation Alone as Postoperative Therapy in Medium-Risk Endometrial Carcinoma-A Prospective Randomized Study. International Journal of Radiation Oncology, Biology, Physics, 82, 1249-1255. https://doi.org/10.1016/j.ijrobp.2011.04.014

[20] de Boer, S.M., Powell, M.E., Mileshkin, L., Katsaros, D., Bessette, P., Haie-Meder, C., Ottevanger, P.B., Ledermann. J.A., Khaw, P., Colombo, A., Fyles, A., Baron, M.H., Kitchener, H.C., Nijman, H.W., Kruitwagen, R.F., Nout, R.A., Verhoeven-Adema, K.W., Smit, V.T., Putter, H. and Creutzberg, C.L. (2016) Toxicity and Quality of Life after Adjuvant Chemoradiotherapy versus Radiotherapy Alone for Women with High-Risk Endometrial Cancer (PORTEC-3): An Open-Label, Multicentre, Randomised, Phase 3 Trial. The Lancet Oncology, 17, 1114-1126. https://doi.org/10.1016/S1470-2045(16)30120-6

[21] Rydzewski, N.R., Strohl, A.E., Donnelly, E.D., Kanis, M.J., Lurain, J.R., Nieves-Neira, W. and Strauss, J.B. (2016) Receipt of Vaginal Brachytherapy Is Associated with Improved Survival in Women with Stage I Endometrioid Adenocarcinoma of the Uterus: A National Cancer Data Base Study. Cancer, 122, 3724-3731. 
https://doi.org/10.1002/cncr.30228

[22] Harkenrider, M.M., Adams, W., Block, A.M., Kliethermes, S., Small Jr., W. and Grover, S. (2017) Improved Overall Survival with Adjuvant Radiotherapy for High-Intermediate and High Risk Stage I Endometrial Cancer. Radiotherapy and Oncology, 122, 452-457. https://doi.org/10.1016/j.radonc.2016.12.003

[23] Wong, A.T., Rineer, J., Schwartz, D., Weiner, J., Safdieh, J., Choi, K. and Schreiber, D. (2017) Patterns of Adjuvant Radiation Usage and Survival Outcomes for Stage I Endometrial Carcinoma in a Large Hospital-Based Cohort. Gynecologic Oncology, 144, 113-118. https://doi.org/10.1016/j.ygyno.2016.11.003

[24] Kong, A., Simera, I., Collingwood, M., Williams, C. and Kitchener, H. (2007) Adjuvant Radiotherapy for Stage I Endometrial Cancer: Systematic Review and Meta-Analysis. Annals of Oncology, 18, 1595-1604.

https://doi.org/10.1093/annonc/mdm066

[25] Sorbe, B., Nordstrom, B., Maenpaa, J., Kuhelj, J., Kuhelj, D., Okkan, S., Delaloye, J.F. and Frankendal, B. (2009) Intravaginal Brachytherapy in FIGO Stage I Low-Risk Endometrial Cancer: A Controlled Randomized Study. International Journal of Gynecological Cancer, 19, 873-878.

https://doi.org/10.1111/IGC.0b013e3181a6c9df

[26] Crosby, M.A., Tward, J.D., Szabo, A., Lee, C.M. and Gaffney, D.K. (2010) Does Brachytherapy Improve Survival in Addition to External Beam Radiation Therapy in Patients with High Risk Stage I and II Endometrial Carcinoma? American Journal of Clinical Oncology, 33, 364-369.

[27] Kasamatsu, T., Onda, T., Katsumata, N., Sawada, M., Yamada, T., Tsunematsu, R., Ohmi, K., Sasajima, Y. and Matsuno, Y. (2003) Prognostic Significance of Positive Peritoneal Cytology in Endometrial Carcinoma Confined to the Uterus. British Journal of Cancer, 88, 245-250. https://doi.org/10.1038/sj.bjc.6600698

[28] Takeshima, N., Nishida, H., Tabata, T., Hirai, Y. and Hasumi, K. (2001) Positive Peritoneal Cytology in Endometrial Cancer: Enhancement of Other Prognostic Indicators. Gynecologic Oncology, 82, 470-473. https://doi.org/10.1006/gyno.2001.6301

[29] Mariani, A., Webb, M.J., Keeney, G.L., Aletti, G. and Podratz, K.C. (2002) Assessment of Prognostic Factors in Stage IIIA Endometrial Cancer. Gynecologic Oncology, 86, 38-44. https://doi.org/10.1006/gyno.2002.6713

[30] Chino, J.P., Jones, E., Berchuck, A., Secord, A.A. and Havrilesky, L.J. (2012) The Influence of Radiation Modality and Lymph Node Dissection on Survival in Early-Stage Endometrial Cancer. International Journal of Radiation Oncology, Biology, Physics, 82, 1872-1879. https://doi.org/10.1016/j.ijrobp.2011.03.054 